\section{Hemoglobin SE disease in Hatay, in the southern part of Turkey}

\author{
Can Acipayam, ${ }^{1}$ Gonul Oktay, ${ }^{2}$ Gul Ilhan, ${ }^{3}$ \\ Mehmet Akif Çürük ${ }^{4}$ \\ 1Department of Pediatric Hematology \\ and Oncology, Mustafa Kemal University \\ School of Medicine, Hatay; \\ ${ }^{2}$ Hemoglobinopathy Center, Hatay \\ Antakya Government Hospital, Hatay; \\ ${ }^{3}$ Department of Hematology, Hatay \\ Antakya Government Hospital, Hatay; \\ ${ }^{4}$ Department of Biochemistry, University \\ of Çukurova, Adana, Turkey
}

\section{Abstract}

Double heterozygosity for hemoglobin ( $\mathrm{Hb})$ $\mathrm{E}$ and $\mathrm{S}$, known as HbSE disease, is a rare, clinically benign condition involving mild hemolysis. Only 25 cases have been reported to date. The current literature generally associates $\mathrm{HbSE}$ with a benign clinical course, although vaso-occlusive complications have been reported. Although only single case reports were previously available, we have observed 20 cases of HbSE and wish to report them. We examined the records of patients presenting to our hemoglobinopathy center in 2001-2013. High performance liquid chromatography (HPLC) was used for hematological assessment of blood samples with ethylenediaminetetraacetic acid. Eight patients were male and 12 female. Mean hemoglobin electrophoresis values were $\mathrm{Hb} \mathrm{Al}$ : $6.3 \%$, Hb E 34.5\%, HbS: 59.5\% and $\mathrm{Hb} \mathrm{F}: 1.9 \%$. Three patients (15\%) were symptomatic with vaso-occlusive crisis and one had cerebral stroke. These were siblings. The patient with cerebral stroke was using hydroxyurea. The incidence of $\mathrm{HbSE}$ disease is rising due to population admixtures and racial intermarriages. Increased numbers of cases of HbSE have been detected after premarital hemoglobinopathy screening in the Antakya and Çukurova regions of Turkey. The aim of this study was to report large numbers of patients with HbSE diagnosed through the routine HPLC method. The secondary aim was to emphasize that severe vaso-occlusive crisis such as infarction symptoms could be seen in HbSE.

\section{Introduction}

Two of the most common variant hemoglobins are hemoglobin ( $\mathrm{Hb}) \mathrm{S}$ (Glu6Val) and hemoglobin E (Glu26Lys). Double heterozygos- ity for $\mathrm{HbE}$ and $\mathrm{HbS}$, known as HbSE disease, is a rare condition, however. ${ }^{1}$ HbSE disease symptoms are variable, ranging from none to different hemolytic episodes. $\mathrm{HbS}$ is common in equatorial Africa, Eastern Saudi Arabia and Central India. ${ }^{1}$ Vascular obliterations occur as a consequence of the sickle cells induced by a lack of oxygen, and infarctions with tissue death can develop in almost all organs (skin, liver, spleen, bone, kidneys, retina, central nervous system, etc.). In general, chronic hemolytic anemia is well tolerated. Aplastic crises occur with severe anemia following viral infections. $^{2}$

$\mathrm{HbE}$ is extremely common in many Asian countries, and is primarily seen in Eastern India, Sri Lanka, Southwest China and Southeast Asia. ${ }^{1,3}$ The most common variant is $\mathrm{HbE}$, which contains lysine substituted for glutamic acid as amino acid 26 in the $\beta$ chain of hemoglobin A. The disease pattern resembles that of $\beta$-thalassemias. $\mathrm{HbE}$ is also unstable and has no clinical significance, meaning that viral infections and medications may lead to hemolysis. Minimal morphological abnormalities of the red cells define the heterozygous state for $\mathrm{HbE}$. Subjects homozygous for $\mathrm{HbE}$ have hypochromic microcytic erythrocytes with significant morphological abnormalities, including increased numbers of target cells. ${ }^{2,4}$ Double heterozygosity for $\mathrm{HbE}$ and $\mathrm{HbS}$, known as $\mathrm{HbSE}$ disease, is a rare, clinically benign condition involving mild hemolysis. ${ }^{3}$ The EtiTurk family in 1957 was the first instance of HbSE disease reported in southern Turkey. HbSE was investigated by Aksoy and confirmed by Lehmann., 5 The electrophoretic pattern shows $60 \% \mathrm{~S}$ and $30 \% \mathrm{E}$. There is a similarity between clinical phenotype and sickle $\beta^{+}$thalassemia. Advancing age can aggravate the medical complications involved. Painful episodes, acute chest syndrome, splenic sequestration and avascular necrosis of the hip have all been observed. ${ }^{7}$

The HbSE double heterozygous state, however, is not common, with only 25 reported cases in the literature. ${ }^{8}$ Ethnic origins are closely associated with the frequency of $\mathrm{Hb} \mathrm{S}$ and other common hemoglobin variants described in southern Turkey. ${ }^{9}$ With population admixture and racial intermarriages, the incidence of $\mathrm{HbSE}$ is increasing in this part of Turkey. Population screening should therefore be performed, and individuals with $\mathrm{HbSE}$ disease should be identified and carefully monitored.

\section{Materials and Methods}

The study was approved by the hemoglobinopathy center of Antakya Government Hospital in Hatay. We examined the records of
Correspondence: Can Acıpayam, Department of Pediatric Hematology and Oncology, Mustafa Kemal University School of Medicine, Zülüflühan Köyü, 31000, Antakya, Hatay, Turkey. Tel. +90.326.229.10.00 - Fax: +90.326.245.56.54.

E-mail: cacipayam@hotmail.com

Key words: hemoglobin S, hemoglobin E, hemoglobin SE, vaso-occlusive crisis, cerebral stroke.

Acknowledgments: this study was supported by the Hemoglobinopathy Center, Hatay Antakya Government Hospital, Turkey.

Conflict of interest: the authors report no conflict of interest.

Received for publication: 21 July 2014

Revision received: 12 January 2015.

Accepted for publication: 29 January 2015.

This work is licensed under a Creative Commons Attribution 3.0 License (by-nc 3.0).

(C) Copyright C. Acipayam et al., 2015

Licensee PAGEPress, Italy

Thalassemia Reports 2015; 5:4597

doi:10.4081/thal.2015.4597

individuals applying to the hemoglobinopathy center from 2001 to 2013 and recorded all diagnoses of compound heterozygosity for $\mathrm{HbS}$ and $\mathrm{HbE}$. We then analyzed the data retrospectively. Clinical data were obtained from patients' medical charts. Two-milliliter blood samples from all patients were collected in ethylenediaminetetraacetic acid vacutainers for estimation of $\mathrm{Hb}$, mean cell volume (MCV) and mean cell hemoglobin $(\mathrm{MCH})$. The tests were performed on a Sysmex XT-2000i Hematology Analyzer (Sysmex Corp., Kobe, Japan) on the same day. We analyzed all samples on the BioRad Variant II HPLC system with a Variant II $\beta$ thalassemia Short Program Reorder Pack (BioRad Lab., Berkley, CA, USA). The Bio-Rad Variant II high performance liquid chromatography (HPLC) system uses the principle of HPLC. The samples are mixed by the Variant II sampling station, diluted with the specific hemolyzing/wash buffer, and injected into an assay-specific analytic cartridge. The Variant II dual pumps deliver a programmed buffer gradient of increasing ionic strength to the cartridge, where the hemoglobin fractions are separated based on their ionic interaction with the cartridge material. The separated hemoglobin fractions pass through a flow cell, where absorbance is measured at $415 \mathrm{~nm}$; background noise is reduced with the use of a secondary wavelength at $690 \mathrm{~nm} .{ }^{10}$ The hemoglobins fall into windows defined by their retention times. A value of more than $3.5 \%$ of $\mathrm{A} 2$ fraction of adult hemoglobin was taken as a cutoff point for determining the $\beta$-thalassemia 
trait. Prominent peaks at the $\mathrm{HbA} 2$ position suggested either raised $\mathrm{HbA} 2$ or $\mathrm{HbE}$. $\mathrm{Hb} \mathrm{A} 2$ plus $\mathrm{Hb} \mathrm{E}$ was suspected in those individuals with very high hemoglobin $\mathrm{A} 2$ values, greater than $10 \% .{ }^{11} \mathrm{HbE}$ was Eluted within the $\mathrm{HbA} 2$ retention time window using the Variant II $\beta$ thalassemia Short Program. Cases were diagnosed as double heterozygous for $\mathrm{HbS}$ and $\mathrm{HbE}$ on the basis of hemoglobin electrophoresis and HPLC results. Clinical and hematological evaluation was carried out using conventional methods. Our findings were compared with those previously reported in the literature.

All data analyses were performed on SPSS software, version 15 (IBM Corp., Armonk, NY, USA). Quantitative data were presented as mean \pm standard deviation.

\section{Results}

Eight (40\%) of the 20 patients were male and $12(60 \%)$ female. Average age at diagnosis was $21.4 \pm 15$ (range 1-49 years). Eighteen patients came from Hatay and the other two from Adana. Family relationships were present in 11 cases (three groups each consisting of three related members, and a further set of two related individuals). Mean hematological profile was $\mathrm{Hb} 12.06 \pm 1.5 \mathrm{~g} / \mathrm{dL}$, MCV $69.9 \pm 5.4 \mathrm{fL}$ and MCH $24.3 \pm 4.06 \mathrm{pg}$. Hemoglobin level was either normal or mildly decreased with a mean of $12.06 \pm 1.5 \mathrm{~g} / \mathrm{dL}$ in the 20 patients diagnosed as double heterozygous for $\mathrm{HbS}$ and $\mathrm{HbE}$. MCV was slightly below the normal range, $69.9 \pm 5.4$ fL. Mean HPLC results were $\mathrm{HbE} 34.5 \%$, HbS $59.5 \%$ and $\mathrm{HbF} 1.9 \%$. Three of the patients (15\%) were symptomatic with vaso-occlusive crisis, and one of these had cerebral stroke. These were siblings. The patient with cerebral stroke was diagnosed at age 11 and was using hydroxyurea. Table 1 shows the clinical, hematological and electrophoretic profiles of all cases of $\mathrm{HbSE}$.

\section{Discussion}

$\mathrm{HbS}$ and $\mathrm{HbE}$ are the most commonly seen variants of hemoglobin. HbSE is rarely encountered and resembles sickle cell disease with a syndrome similar to sickle $\beta^{+}$thalassemia. These sickling-related complications are seen frequently in adults aged 20 or more, but rarely in children. ${ }^{1,7,12}$

Severity of HbSE disease significantly depends on $\mathrm{HbF}$ expression, making Asian $\mathrm{HbS}$ and $\mathrm{HbE}$ combinations less severe than African $\mathrm{HbS} / \mathrm{HbE}$. Infarctive symptoms, as observed in the present cohort, should not be underestimated. Despite the reported vaso-occlusive complications, the current literature mostly refers to HbSE as benign. ${ }^{13}$ Several cases with more severe clinical presentations have also been reported. Complications such as acute chest syndrome, painful episodes, splenic infarcts, hematuria, bone pain, avascular necrosis of the hip and shoulder, jaundice hepatic and ocular complications have been reported in these cases. ${ }^{3,14,15}$ Ganesh et al. ${ }^{3}$ described a young man with sickle cell-hemoglobin $\mathrm{E}$ (HbSE) disease who developed multiple episodes of re-bleeding, persistent elevation of intraocular pressure and sickle cell retinopathy following traumatic hyphema. Eichhorn et al. ${ }^{16}$ reported a case of double heterozygosity manifesting as an infarction sickle cell-like crisis with acute chest syndrome and reversible bone marrow necrosis. It is important to note that these complications were linked to parvovirus B19 infection. Rayburg et al. ${ }^{13}$ reported a child with $\mathrm{HbSE}$ disease with fatal bone marrow embolism. Knox-Macaulay et al. ${ }^{17}$ reported 12 cases with SE compound heterozygotes. In that report sickling-related complications included acute chest syndrome $(1 / 12)$, serious vaso-occlusive skeletal pain $(2 / 12)$, frontal bossing (1/12) and repeated infections of the urinary tract $(1 / 12)$. The rest were asymptomatic.

Vaso-occlusive crisis has previously been reported in this disease. In two of our three patients with vaso-occlusive crisis, painful crisis were mild. Nevertheless, we present a case of double heterozygosity manifesting as an infarction sickle cell-like crisis with cerebral stroke. Hemoglobin SE disease with cerebral

Table 1. Clinical and laboratory characteristics of patients with hemoglobin $S$ and $E$.

\begin{tabular}{|c|c|c|c|c|c|c|c|}
\hline Case no. & Hb (g/dL) & MCV (fL) & MCH (pg) & HbS (\%) & HbE (\%) & HbF (\%) & Presenting symptoms \\
\hline 1 & 12.2 & 68.2 & 23.7 & 60 & 40 & 0 & Asymptomatic \\
\hline 2 & 11 & 74.7 & 25.5 & 63.8 & 36.6 & 1.4 & Asymptomatic \\
\hline 3 & 11.7 & 67.7 & 23.3 & 62.2 & 34.5 & 1.5 & Asymptomatic \\
\hline 4 & 11.5 & 72.9 & 24.5 & 61.7 & 35.1 & 0.9 & Asymptomatic \\
\hline 5 & 12.6 & 75.5 & 25.5 & 52.6 & 34.5 & 2.1 & Vaso-occlusive crisis (cerebral stroke) \\
\hline 6 & 12.1 & 72.9 & 2 & 59.7 & 37.2 & 0.7 & Vaso-occlusive crisis \\
\hline 7 & 12.1 & 68.8 & 22.2 & 58.8 & 34 & 0.6 & Vaso-occlusive crisis \\
\hline 8 & 13.3 & 69.4 & 23.8 & 61.1 & 33.4 & 0.6 & Asymptomatic \\
\hline 9 & 10.4 & 73.7 & 25 & 61.1 & 33.8 & 0.8 & Asymptomatic \\
\hline 10 & 11.2 & 72.3 & 23.6 & 61.6 & 39.8 & 1,1 & Asymptomatic \\
\hline 11 & 13.5 & 72.9 & 24.8 & 59 & 37.6 & 2.5 & Asymptomatic \\
\hline 12 & 11.9 & 69.5 & 23.7 & 58.1 & 33.6 & 2.8 & Asymptomatic \\
\hline 13 & 11.3 & 61.7 & 20.5 & 57.7 & 33 & 4.8 & Asymptomatic \\
\hline 14 & 10.3 & 57.9 & 19.8 & 56.9 & 34.4 & 6.3 & Asymptomatic \\
\hline 15 & 14.8 & 69.0 & 23.3 & 61.5 & 29.7 & 0.4 & Asymptomatic \\
\hline 16 & 10.7 & 75.2 & 25.4 & 60.6 & 33.3 & 1.1 & Asymptomatic \\
\hline 17 & 15.8 & 77.4 & 26.6 & 59.5 & 33.2 & 0.7 & Asymptomatic \\
\hline 18 & 13.5 & 74.1 & 39.18 & 59.8 & 32.3 & 0.9 & Asymptomatic \\
\hline 19 & 11.4 & 61.5 & 20.4 & 59.1 & 30.4 & 1.3 & Asymptomatic \\
\hline 20 & 10 & 58.0 & 19.5 & 55.4 & 32.5 & 5.9 & Asymptomatic \\
\hline
\end{tabular}

$\mathrm{Hb}$, hemoglobin; MCV, mean corpuscular volume; MCH, mean corpuscular hemoglobin. 
stroke has not previously been reported. This case involved sequela after stroke. In the light of previous studies and our case with cerebral stroke, the clinical presentation of HbSE disease demonstrates that it can be more serious than previously thought. Our cases, as well as other reports concerning HbSE, show that the clinical picture may in fact be serious in some patients, with the potential for life-threatening vaso-occlusive complications, even in childhood. The patient with cerebral stroke was using hydroxyurea, the drug employed for the treatment of sickle cell anemia. Adult patients with $\mathrm{HbSE}$ disease who have repeated or severe complications associated with sickle cell anemia can be treated with hydroxyurea. ${ }^{1}$ The incidence of vaso-occlusive and other complications of sickle cell disease for patients with $\mathrm{HbSE}$ is unknown. Increasing clinical experience and epidemiological investigation will help to establish the complications and severity of $\mathrm{HbSE}$ disease.

\section{Conclusions}

The clinical description of HbSE disease as a mild syndrome is based on case reports. We describe 20 cases with $\mathrm{HbSE}$ disease. Our area has a high incidence of hemoglobinopathy ( $\mathrm{HbS}$ and $\mathrm{HbE}$ ). Newborn screening for hemoglobinopathies has been performed in New England in the United States, and infants at risk for serious complications have been identified, thus permitting appropriate healthcare. ${ }^{18}$ In our region premarital (or preconceptional) and neonatal screening programs are recommended because hemoglobin SE disease can involve severe complications, such as cerebral stroke.

\section{Limitations}

First, this study was limited by its retrospective nature. The results were obtained through retrospective collection of data. Since the study was not planned prospectively $\mathrm{HbS}$ by sickle test and $\mathrm{HbE}$ by molecular diagnosis could not be confirmed. In our region, it is observed that numbers of double heterozygous for $\mathrm{HbS}$ and $\mathrm{HbE}$ cases are great. Our hospital is a hospital, which renders second-level medical services. It also performs the services for a huge number of patients. We do not have another method than HPLC in order to diagnose this disease. Provisional diagnosis of $\mathrm{HbS} / \mathrm{E}$ is very easy on HPLC or capillary electrophoresis. In our study, because of the technical inadequacies, confirmation could not be performed by sickle test or DNA analysis. In future, we can refer tertiary university hospitals to patients with suspicion of HPLC and HbSE for sickle test and molecular diagnosis.

\section{References}

1. Masiello D, Heeney MM, Adewoye AH, et al. Hemoglobin SE disease: a concise review. Am J Hematol 2007;82:643-9.

2. Kohne E. Hemoglobinopathies: clinical manifestations, diagnosis, and treatment. Dtsch Arztebl Int 2011;108:532-40.

3. Ganesh A, al-Habsi NS, al-Alawi FK, et al. Traumatic hyphaema and sickle cell retinopathy in a patient with sickle cellhaemoglobin E (HbSE) disease. Eye (Lond) 2000;14:397-400.

4. Fucharoen S, Weatherall DJ. The hemoglobin E thalassemias. Cold Spring Harb Perspect Med 2012;1;2.

5. Aksoy M. The hemoglobin E syndromes. II. Sickle-cell-hemoglobin E disease. Blood 1960;15:610-3.

6. Aksoy M, Lehmann H. The first observation of sickle-cell haemoglobin E disease. Nature 1957;179:1248-9.

7. Vichinsky E. Hemoglobin e syndromes. Hematol Am Soc Hematol Educ Program 2007;79-83.

8. Mishra P, Pati HP, Chatterjee T, et al. Hb SE disease: a clinico-hematological profile.
Ann Hematol 2005;84:667-70.

9. Yüregir GT, Donma 0, Dikmen N, et al. Population studies of hemoglobin $\mathrm{S}$ and other variants in Çukurova, the southern part of Turkey. Nihon Ketsueki Gakkai Zasshi 1987;50:757-65.

10. Joutovsky A, Hadzi-Nesic J, Nardi MA. HPLC retention time as a diagnostic tool for hemoglobin variants and hemoglobinopathies: a study of 60000 samples in a clinical diagnostic laboratory. Clin Chem 2004;50:1736-47.

11. Balgir RS. Is hemoglobin $\mathrm{E}$ gene widely spread in the state of madhya pradesh in central India? Evidence from five typical families. Mediterr J Hematol Infect Dis 2014;6:e2014060.

12. Dani AA, Shrikhande AV. Double heterozygous for hemoglobin $\mathrm{S}$ and hemoglobin $\mathrm{E}$ a case report from central India. Indian $\mathrm{J}$ Hematol Blood Transfus 2007;23:119-21.

13. Rayburg M, Kalinyak KA, Towbin AJ, et al. Fatal bone marrow embolism in a child with hemoglobin SE disease. Am J Hematol 2010;85:182-4.

14. Gürkan E. Vaso-occlusive manifestations in a patient with sickle cell-hemoglobin $\mathrm{E}$ (HbSE) disease. Am J Hematol 2006;81: 149.

15. George E, Iqbal QM. Hb ES presenting as avascular necrosis. Southeast Asian J Trop Med Public Health 1978;9:568-70.

16. Eichhorn RF, Buurke EJ, Blok P, et al. Sickle cell-like crisis and bone marrow necrosis associated with parvovirus B19 infection and heterozygosity for haemoglobins S and E. J Intern Med 1999;245: 103-6.

17. Knox-Macaulay HH, Ahmed MM, Gravell D, et al. Sickle cell-haemoglobin E (HbSE) compound heterozygosity: a clinical and haematological study. Int J Lab Hematol 2007;29:292-301.

18. Thornburg CD, Steinberg MH, Chui DH. Hemoglobin SE disease in Maine, and severe thalassemia in New Hampshire. J Pediatr Hematol Oncol 2009;31:307. 